\title{
Stenotic false lumen as inflow of coronary aneurysm and full-metal jacket
}

\author{
Suguru Ohira, $\mathrm{MD}, \mathrm{PhD},{ }^{\mathrm{a}}$ Hitoshi Yaku, $\mathrm{MD}, \mathrm{PhD},{ }^{\mathrm{a}}$ and Shuichiro Takanashi, $\mathrm{MD}, \mathrm{PhD}^{\mathrm{b}}$
}

\footnotetext{
From the ${ }^{\mathrm{a}}$ Department of Cardiovascular Surgery, Kyoto Prefectural University of Medicine, Kyoto; and ${ }^{\mathrm{b}}$ Department of Cardiovascular Surgery, Sakakibara Heart Institute, Tokyo, Japan.

Disclosures: Authors have nothing to disclose with regard to commercial support.

Received for publication April 7, 2017; revisions received May 4, 2017; accepted for publication June 2, 2017; available ahead of print July 6, 2017.

Address for reprints: Suguru Ohira, MD, PhD, Department of Cardiovascular Surgery, Kyoto Prefectural University of Medicine, 465 Kajii-cho, Kawaramachi-Hirokoji, Kamigyo-ku, Kyoto 602-8566, Japan (E-mail: s-ohira@koto.kpu-m.ac.jp).

J Thorac Cardiovasc Surg 2018;155:225-6

$0022-5223 / \$ 36.00$

Copyright (C) 2017 by The American Association for Thoracic Surgery

http://dx.doi.org/10.1016/j.jtcvs.2017.06.006
}

Video clip is available online.

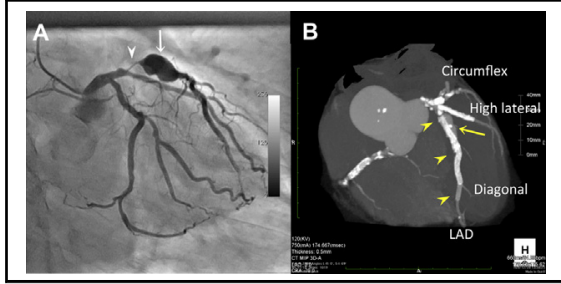

A stenotic false lumen as an inflow of the coronary aneurysm with a "full-metal jacket."

\section{Central Message}

A rare case of angina due to a markedly stenotic false lumen as an inflow of a coronary aneurysm with a full-metal jacket required extensive reconstruction of the left anterior descending artery is discussed.

See Editorial Commentary page 227.
A 75-year-old man developed a coronary aneurysm after multiple procedures of bare-metal stenting for left anterior descending artery (LAD) occlusion 16 years previously; however, the proximal LAD including stents subsequently became occluded. The aneurysm and distal LAD were supplied through a false lumen that became markedly stenotic with accompanying angina during the previous 6 months before presentation (Figure 1, A, and Video 1). Because

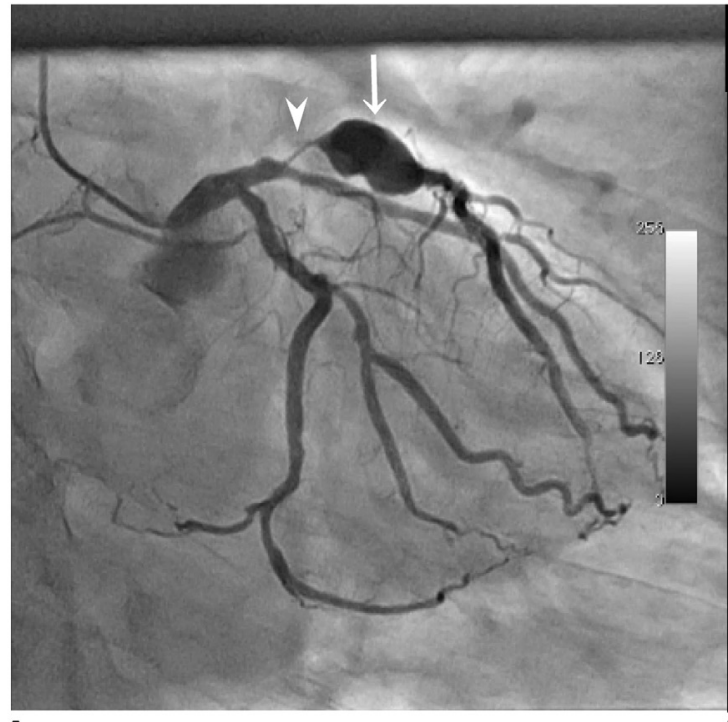

A

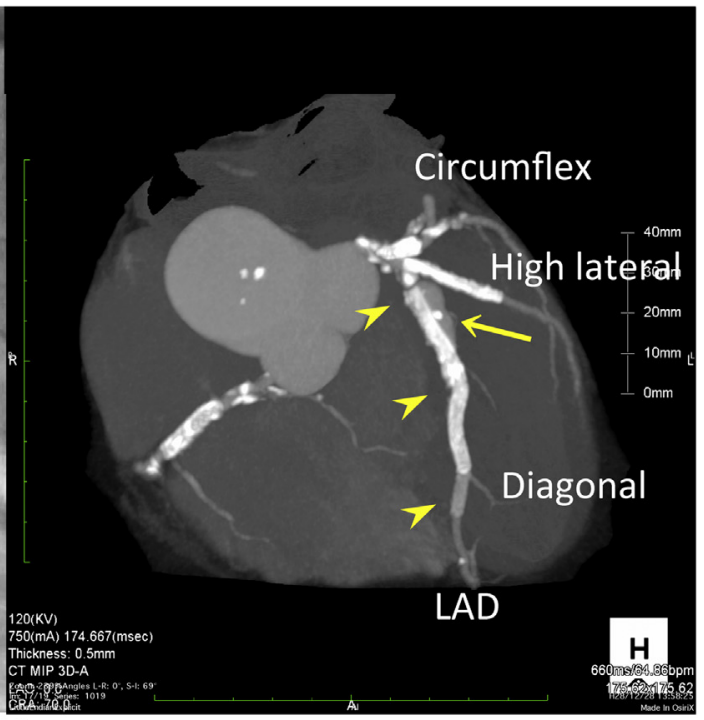

B

FIGURE 1. Preoperative coronary angiography. A, A coronary aneurysm (arrow) in the LAD with marked stenosis of the false lumen (arrowhead). B, Multiple stents (arrowheads) were placed from an aneurysm (arrow) to the distal LAD beyond the diagonal branch. LAD, Left anterior descending artery. 


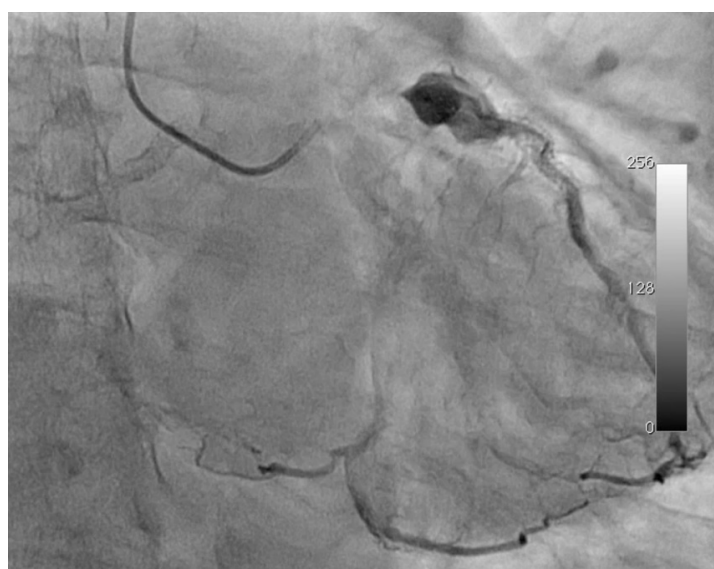

VIDEO 1. Preoperative angiography showed a coronary aneurysm in the LAD with stenosis of the false lumen. Video available at: http:// www.jtcvsonline.org/article/S0022-5223(17)31173-X/addons.

multiple stents were placed from a proximal part of the aneurysm to distal LAD beyond the last diagonal branch (Figure 1, B), aneurysm resection, stent removal with endarterectomy, and onlay patch grafting of the LAD $(6.5 \mathrm{~cm})$

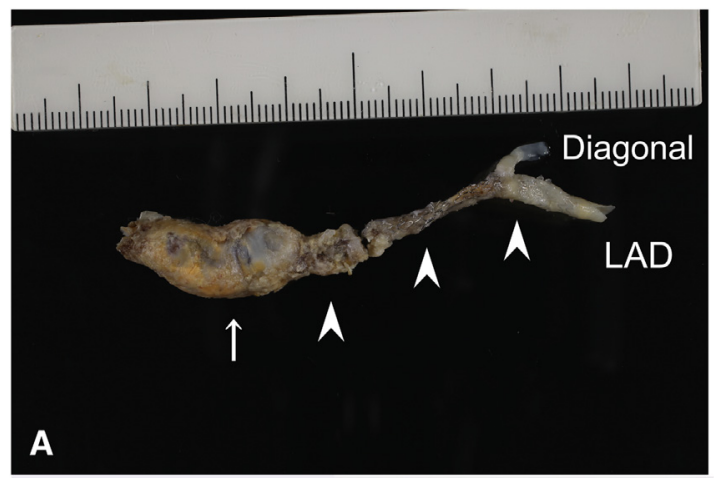

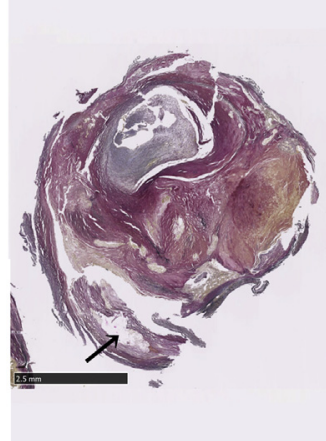

B

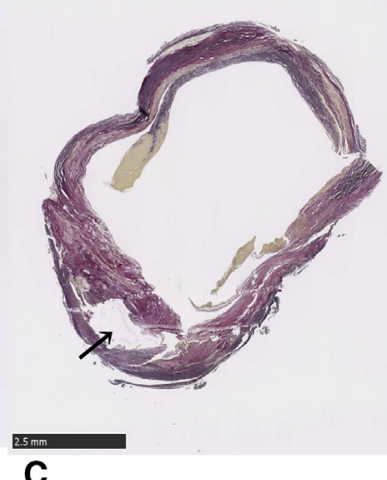

C
FIGURE 2. Pictures of (A) the endarterectomized core of the LAD and aneurysm (arrow) with stents (arrowheads). Elastic Van Gieson stain revealed (B) an occluded true lumen and (C) true coronary aneurysm. Arrows show the false lumen. $L A D$, Left anterior descending artery.

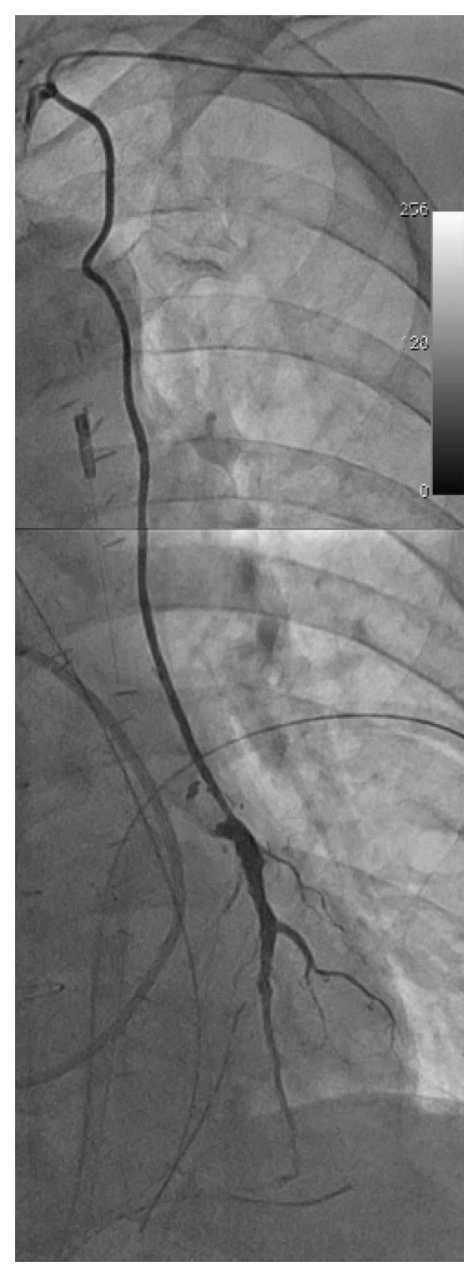

FIGURE 3. Postoperative angiography showed excellent flow of the left internal thoracic artery with patent septal and diagonal branches.

with left internal thoracic artery were performed (Figure 2, A). ${ }^{1}$ A histopathologic examination showed marked stenosis of the false lumen and true coronary aneurysm (Figure 2, $B$ and $C$ ). ${ }^{2}$ Postoperative angiography showed excellent flow of the reconstructed LAD and in situ graft (Figure 3).

\section{References}

1. Fukui T, Tabata M, Taguri M, Manabe S, Morita S, Takanashi S. Extensive reconstruction of the left anterior descending coronary artery with an internal thoracic artery graft. Ann Thorac Surg. 2011;91:445-51.

2. Wilson GJ, Nakazawa G, Schwartz RS, Huibregtse B, Poff B, Herbst TJ, et al. Comparison of inflammatory response after implantation of sirolimus-and paclitaxel-eluting stents in porcine coronary arteries. Circulation. 2009;120:141-9. 